\title{
Mid-twenty-first century climate change in the Central United States. Part II: Climate change processes
}

\author{
C. M. Patricola $\cdot$ K. H. Cook
}

Received: 28 September 2011 / Accepted: 23 April 2012/Published online: 24 May 2012

(C) The Author(s) 2012. This article is published with open access at Springerlink.com

\begin{abstract}
Ensemble regional model simulations over the central US with $30-\mathrm{km}$ resolution are analyzed to investigate the physical processes of projected precipitation changes in the mid-twenty-first century under greenhouse gas forcing. An atmospheric moisture balance is constructed, and changes in the diurnal cycle are evaluated. Wetter conditions over the central US in April and May occur most strongly in the afternoon and evening, supported primarily by moisture convergence by transient eddy activity, indicating enhanced daytime convection. In June, increased rainfall over the northern Great Plains is strongest from 0000 to $0600 \mathrm{LT}$. It is supported by positive changes in stationary meridional moisture convergence related to a strengthening of the GPLLJ accompanied by an intensification of the western extension of the North Atlantic subtropical high. In the Midwest, decreased rainfall is strongest at $1500 \mathrm{LT}$ and $0000 \mathrm{LT}$. Both a suppression of daytime convection as well as changes in the zonal flow in the GPLLJ exit region are important. Future drying over the northern Great Plains in summer is triggered by weakened daytime convection, and persists throughout August and September when a deficit in soil
\end{abstract}

C. M. Patricola

Department of Earth and Atmospheric Sciences, Cornell

University, Ithaca, NY 14853, USA

C. M. Patricola ( $\square)$

Department of Atmospheric Sciences, Texas A\&M University, 3150 TAMU, College Station, TX 77843-3150, USA

e-mail: cmd58@cornell.edu

K. H. Cook

Jackson School of Geosciences, The University of Texas

at Austin, 1 University Station, C1100, Austin, TX 78712, USA moisture develops and land-atmosphere feedbacks become increasingly important.

Keywords Regional climate model · Great Plains · Precipitation - Great Plains low-level jet - Diurnal cycle . Climate change

\section{Introduction}

This paper follows Patricola and Cook (2012; hereafter PCI), who presented projections of climate change for the central US at $30-\mathrm{km}$ resolution using a regional climate model forced with increased atmospheric $\mathrm{CO}_{2}$ and boundary condition anomalies derived from coupled GCM simulations of the Fourth Assessment Report of the Intergovernmental Panel on Climate Change (IPCC AR4). As reviewed below, PCI report projected changes in climatological and extreme rainfall, and evaluated confidence in those projections through ensemble methodology and comparison with other regional and global model simulations. The purpose of this paper is to understand the predicted changes in physical processes associated with the central US precipitation changes to add to the evaluation of confidence in the projections.

A focus of the analysis is on changes in the Great Plains low-level jet (GPLLJ). This feature provides a physical connection between space scales, and can help relate changes in the large-scale circulation, such as those caused by global-scale greenhouse gas forcing, and regional rainfall. For example, if we can understand how changes in the GPLLJ are related to large-scale climate change, and also how precipitation changes are related to changes in the GPLLJ, then we can attribute changes in rainfall to greenhouse gas forcing. 
The following section reviews PCI and provides background on the GPLLJ and its relationship to central US precipitation and the large-scale circulation. Relationships between SSTs and precipitation, the role of land-atmosphere feedbacks in prolonging drought over the central US, and the climatology and variability of the present day hydrological cycle are also reviewed. Section 3 explains the analysis methods used. PCI validate the model simulations, and additional validation in support of the analysis here is included in Sect. 4. The climate change processes that lead to simulated changes in central US rainfall are discussed in Sect. 5, and Sect. 6 contains conclusions.

\section{Background}

PCI project changes in central US rainfall regimes for the mid-twenty-first century under greenhouse gas forcing including wetter conditions in the spring and drying in the summer. These changes in seasonal rainfall are accompanied by changes in extreme precipitation events. A greater potential for flooding is suggested by simulated changes in rainfall rates. Confidence in these projections was bolstered by general agreement with the dynamically-downscaled $50-\mathrm{km}$ regional model simulations of the North American Regional Climate Change Assessment Program (NARCAPP) and with 200-km AOGCM simulations prepared for the IPCC AR4. Further evaluation and attribution of the simulated changes in this paper focuses on the processes of climate change, including associations with the GPLLJ and the North Atlantic subtropical high (NASH).

The climatological GPLLJ is a meridional jet that traverses the central US east of the Rocky Mountain topography with a core at about $100^{\circ} \mathrm{W}$ and $900-850 \mathrm{hPa}$ (Bonner 1968). It is a prominent source of moisture in spring and summer, transporting moisture from the Gulf of Mexico to the interior of the central US. The GPLLJ is strongest in summer and, like precipitation, has a strong diurnal cycle that peaks around $0300 \mathrm{LT}$. While the jet is well-formed in monthly, coarse-resolution climatologies, in reality it is composed of discrete events that do not necessarily occur daily (e.g., Wu and Raman 1998), with observed non-negligible moisture and momentum transports on small space scales (Tollerud et al. 2008).

Experiments with an AGCM and linear and nonlinear stationary wave models suggest that the climatological GPLLJ is primarily maintained by transient vorticity forcing due to the modification of transient eddies by topography, specifically the interactions of the easterly wind along the southern edge of the NASH with the Sierra Oriental (Ting and Wang 2006). The nocturnal maximum in the GPLLJ is produced by the diurnal oscillation of the pressure gradient force and vertical diffusion, as suggested by AGCM simulations (Jiang et al. 2007). This mechanism of the diurnal oscillation of vertical diffusion was proposed by Blackadar (1957) and is initiated by the abrupt reduction of friction at sunset. Holton (1967) theorized the importance of the diurnal oscillation of the pressure gradient force, which is caused by differential heating and cooling over the topography. Maximum afternoon heating over the topography induces easterly winds on the eastern side of the mountain and, due to the inertial oscillation, the flow curves to the north with a maximum southerly wind speed at midnight.

Since the GPLLJ transports large amounts of moisture into the central US, it plays an important role in generating that region's warm season rainfall. The association between jet strength and extreme precipitation events is well known. The Great Plains flood of 1993 and drought of 1988 related strongly to variations in GPLLJ strength and associated moisture transport and convergence (Weaver et al. 2009a). Enhanced moisture transport by the GPLLJ is also found to support composites of observed wet events (Mo et al. 1997).

Cook et al. (2008b) examine predicted changes in the GPLLJ in AOGCMs that were run for the IPCC AR4. Nearly all of a subset of 11 models predict an increase in the GPLLJ strength during April-June, which is related to a strengthening and westward expansion of the NASH that is associated with greater warming over the continental US compared to the subtropical Atlantic Ocean. The importance of zonal land/sea temperature gradients in modifying the strength of the GPLLJ is supported by idealized GCM experiments that produce a stronger GPLLJ and enhanced Great Plains rainfall as a result of cool Atlantic SSTAs (Weaver et al. 2009b).

The North Atlantic Oscillation (NAO), which is a measure of a shift in atmospheric mass between the NASH and Icelandic low, also contributes to present day variability in warm season central US precipitation. Conditions during the warm season in the upper (lower) Midwest tend to be drier (wetter) during the positive phase of the NAO, which is characterized by a strong NASH and Icelandic low (Weaver and Nigam 2008). This may be related to North Atlantic SSTs, as Paeth et al. (2003) find that the positive (negative) phase of the NAO tends to occur with cooler (warmer) subtropical Atlantic SSTs and warmer (cooler) Atlantic SSTs between $30^{\circ} \mathrm{N}$ and $45^{\circ} \mathrm{N}$.

Several studies document the role of North Atlantic and tropical Pacific SSTs in contributing to North American drought. Observations indicate that Great Plains droughts are linked with cool SSTs in the tropical Pacific and, through influence of the NAO on the NASH, the North Atlantic (Ruiz-Barradas and Nigam 2005). Similarly, Great Plains droughts lasting less than 3 months are most closely related to simultaneous cool tropical Pacific and 
subtropical North Atlantic SSTAs, while droughts lasting 6 months or more are related to simultaneous and preceding (by 6 months) Indian and tropical Pacific SSTs and simultaneous SSTAs in the subtropical North Atlantic (Wu and Kinter 2009). Trenberth et al. (1988) and Trenberth and Branstator (1992) linked the onset of the central US drought of 1988 to SSTAs in the tropical Pacific, which forced a shift in the intertropical convergence zone, producing atmospheric heating anomalies that supported the anomalous North American circulation that initiated the drought. The drought conditions of the 1930s dust bowl are linked strongly to Atlantic SSTAs and, to a lesser extent, Pacific SSTAs in an observational analysis (Nigam et al. 2011), and are also attributed to both cool tropical Pacific and warm tropical Atlantic SSTAs on the decadal time scale through AGCM simulations, although there is a southward bias in the location of the simulated drought (Schubert et al. 2004; Seager et al. 2008). Cook et al. (2008a) find that with SST forcing alone, model simulations are unable to reproduce the intensity and spatial pattern of the 1930s drought, but that accounting for increased dust aerosol loading enhances the modeled severity of the drought and improves the location. Economic and development issues also contributed to the drought of the dust bowl era (Egan 2006), so SST forcing in models cannot be expected to capture the full signal.

Atmospheric variability may also play a significant role in US drought. Hoerling et al. (2009) find that drought over the southern Great Plains is related to SSTs, especially strong La Niña, while drought over the northern Great Plains is less sensitive to SSTs and may be more attributable to random atmospheric variability. Combined global and regional modeling suggests that different physical processes contributed to the onset, maintenance, and termination of the Oklahoma-Texas drought of 1998. Hong and Kalnay (2000) suggest that SSTAs most strongly contributed to the early rainfall deficit, with secondary contributions from the atmospheric conditions associated with the decaying warm El Niño event, while a strong land-atmosphere feedback prolonged the drought through decreased soil moisture and evaporation.

Many other studies find that drought conditions are sustained and intensified by land-atmosphere interactions. Wu and Kinter (2009) attribute positive land-atmosphere feedbacks through soil moisture and precipitation to extending the persistence of drought, and Schubert et al. (2004) find that land-surface interactions enhanced the severity of the 1930s drought. AGCMs simulate strong land-atmosphere coupling over the central Great Plains region (Koster et al. 2004), although the models demonstrate a large spread and many have biased surface fluxes, leading to a questionable representation of land-atmosphere feedbacks (Dirmeyer et al. 2006). Regional climate model simulations can also produce strong land-atmosphere feedbacks, with coupling (through soil moisture and convective rainfall) dominating summer precipitation variability over the northern, but not southern, Great Plains (Zhang et al. 2008).

There is evidence that the role of soil moisture and evaporation in supporting precipitation anomalies depends on soil wetness. AGCM simulations suggest that long-term wet conditions in the Great Plains are more predictable than droughts due to a dependence of the strength of landatmosphere coupling on soil conditions, such that dry soil conditions increase the strength of coupling (Schubert et al. 2007). This dependence on soil moisture is also supported by observations, which demonstrate that evaporation supplied $41 \%$ of the rainfall over the Mississippi River basin during the drought of April-July of 1988, but only $33 \%$ during the flood of April-July of 1993 (Dirmeyer and Brubaker 1999). In addition, at the maximum of the flood in July of 1993, water recycling was reduced and moisture transport from the Gulf of Mexico was increased, while at the peak of the 1988 drought in June, water recycling was at a maximum.

Comparison of observations/reanalysis and model simulations suggests there may be too much precipitation recycling in models. Observations and reanalysis indicate that changes in moisture flux convergence are of primary importance in generating precipitation variability over the Great Plains (Roads et al. 1994). This finding is consistent in the 40-year European Centre for Medium-Range Weather Forecasts (ECMWF) Re-Analysis (ERA-40), however, in the National Centers for Environmental Prediction (NCEP) reanalysis and model simulations, evaporation contributes to more than half the precipitation anomalies (Ruiz-Barradas and Nigam 2005).

In the climatology, moisture flux convergence is generally a more minor component of the water balance. Observed/reanalyzed, evaporation ( $\sim 5 \mathrm{~mm} /$ day) is greater than precipitation ( $\sim 4 \mathrm{~mm} /$ day) and moisture flux convergence is weakly (up to $2 \mathrm{~mm} /$ day) negative over the Midwest $\left(37^{\circ} \mathrm{N}-42^{\circ} \mathrm{N}, 94^{\circ} \mathrm{W}-80^{\circ} \mathrm{W}\right)$, whereas positive moisture flux convergence contributes up to $3 \mathrm{~mm} /$ day over the Great Plains $\left(37^{\circ} \mathrm{N}-48^{\circ} \mathrm{N}, 103^{\circ} \mathrm{W}-94^{\circ} \mathrm{W}\right.$; Roads et al. 1994). Similarly, evaporation exceeds precipitation, and moisture flux convergence is relatively weakly negative over the Great Plains $\left(35^{\circ} \mathrm{N}-45^{\circ} \mathrm{N}, 100^{\circ} \mathrm{W}-90^{\circ} \mathrm{W}\right)$ in the summer climatology of three reanalyses (Nigam and Ruiz-Barradas 2006), namely, the NCEP, ERA-40, and North American Regional Reanalysis (NARR). Nigam and Ruiz-Barradas (2006) point out that the ERA-40 and NARR have considerable water budget imbalances of 1.5 and $2.5 \mathrm{~mm} /$ day, respectively, which are largest in late spring through early summer and pose a challenge in understanding hydroclimate. 


\section{Methodology}

Twenty annual integrations representing the late twentieth century (1981-2000), "L20C," and mid-twenty-first century (2041-2060), "M21C," are conducted with a regional climate model (RCM), the Weather Research and Forecasting Model (WRF; Skamarock et al. 2008). Simulations are run at $30 \mathrm{~km}$ resolution on a domain over the central US nested within a $90 \mathrm{~km}$ domain (see Fig. 4 in PCI). Lateral boundary conditions for L20C are prescribed from the National Center for Environmental Prediction/Department of Energy Atmospheric Model Intercomparison Project II (NCEP/DOE AMIP-II) Reanalysis (Kanamitsu et al. 2002) and SST is prescribed from the European Centre for Medium-Range Weather Forecasts (ECMWF 2002) reanalysis to reduce model bias. Boundary conditions for M21C are created by adding anomalies from the average of six AOGCMs (CCCMA_CGCM3.1, CNRM-CM3, GFDL-CM2.0, ECHAM5/MPI-OM, NCAR_PCM, and UKMO-HadCM3) of the IPCC AR4 forced by the SRESA2 emissions scenario (IPCC 2000) to the reanalysis, and greenhouse gas concentrations for M21C are based on the SRESA2 scenario as well. For details about the model parameters and simulation design, please refer to Section 3 in PCI.

To better understand the connections between future precipitation and circulation changes, a moisture budget analysis similar to that derived in Lenters and Cook (1995) is presented in Sect. 5. The moisture budget is expressed as

$P=E+C+A+T C+T A+R$,

and includes contributions to precipitation $(P)$ from evaporation $(E)$, vertically-integrated stationary moisture convergence $(C)$ and advection $(A)$, moisture convergence due to transient eddies $(T C)$, moisture advection due to transient eddies $(T A)$, and the residual $(R)$, which includes topographic effects and numerical error. The contribution from the vertically-integrated stationary moisture convergence, hereafter referred to as "stationary moisture convergence" is

$C=-\frac{1}{g \rho_{w}} \sum_{p=\bar{p}_{s}}^{100 \mathrm{hPa}}\left(\bar{q} \nabla_{h} \cdot \bar{V}\right) \Delta p$

where $g$ is the acceleration due to gravity, $\rho_{w}$ is the density of water, $p$ is pressure, $\bar{p}_{s}$ is the monthly-averaged surface pressure, $\bar{q}$ is the monthly-averaged water vapor mixing ratio, $\bar{V}$ is the monthly-averaged horizontal wind vector, and $\nabla_{h}$ is the horizontal divergence operator. Note that, as pointed out by Lenters and Cook (1995), the "moisture convergence" term refers to the vertically-integrated product of the mixing ratio and the wind convergence.

The vertically-integrated stationary moisture advection, hereafter referred to as the "stationary moisture advection" is
$A=-\frac{1}{g \rho_{w}} \sum_{p=\bar{p}_{s}}^{100 \mathrm{hPa}}\left(\bar{V} \cdot \nabla_{h} \bar{q}\right) \Delta p$.

The vertically-integrated moisture convergence due to transient eddies is

$T C=-\frac{1}{g \rho_{w}} \sum_{p=p_{s}}^{100 \mathrm{hPa}}\left(q^{\prime} \nabla_{h} \cdot V^{\prime}\right) \Delta p$

where $V^{\prime}$ is the perturbation horizontal wind vector defined as $V^{\prime}=V-\bar{V}$ and $q^{\prime}$ is the perturbation water vapor mixing ratio defined as $q^{\prime}=q-\bar{q}$. The verticallyintegrated moisture advection due to transient eddies is

$T A=-\frac{1}{g \rho_{w}} \sum_{p=p_{s}}^{100 \mathrm{hPa}}\left(V^{\prime} \cdot \nabla_{h} q^{\prime}\right) \Delta p$

In addition to the moisture budget analysis, we analyze changes in low-level (surface to $750 \mathrm{hPa}$ ) mass-weighted vertically integrated moisture transport, hereafter referred to as "low-level moisture transport" and expressed as

$\frac{1}{g} \sum_{p=\bar{p}_{s}}^{750 \mathrm{hPa}}\left(\bar{q} \bar{V}_{h}\right) \Delta p$

\section{Model validation}

In addition to the more general model validation in PCI, the GPLLJ and NASH are validated here since these circulation features are important in understanding the central US precipitation predictions. We use the NARR (Mesinger et al. 2006) to validate the GPLLJ since its $32 \mathrm{~km}$ horizontal resolution is much finer than that of the $2.5^{\circ} \mathrm{NCEP}$ II reanalysis. However, the NARR does not cover the entire parent domain of the RCM simulation, so the NCEP-II is used to validate the NASH.

The regional model reproduces the characteristics of the GPLLJ and its seasonal cycle exceptionally well. Figure 1 shows a vertical cross section of the 1981-2000 climatological monthly meridional wind averaged $28^{\circ} \mathrm{N}-32^{\circ} \mathrm{N}$ from the NARR (Fig. 1a-d) and the nested domain of L20C (Fig. 1e-h) from May through August. The reanalyzed core of the GPLLJ is located between $103^{\circ} \mathrm{W}-95^{\circ} \mathrm{W}$ and $950-850 \mathrm{hPa}$ and reaches a maximum of $6.5 \mathrm{~m} / \mathrm{s}$ in June and July. The RCM captures the seasonal cycle of the GPLLJ well, with a stronger $(\sim 1 \mathrm{~m} / \mathrm{s})$ jet peaking in June and July at $7.5 \mathrm{~m} / \mathrm{s}$. In addition, the RCM simulates the alignment of the GPLLJ along the topography, which is often not captured in GCM simulations with coarser horizontal resolution (e.g., Fig. 2 of Cook et al. 2008b), and places the core location realistically, but slightly lower.

In addition to realistically representing the seasonal variation of the GPLLJ, the L20C simulation captures 
(a)

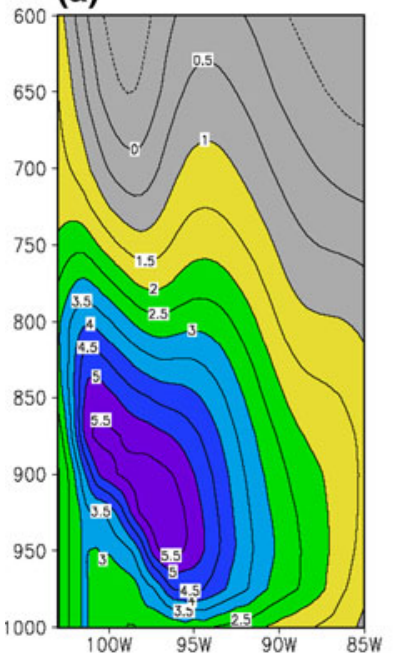

(e)

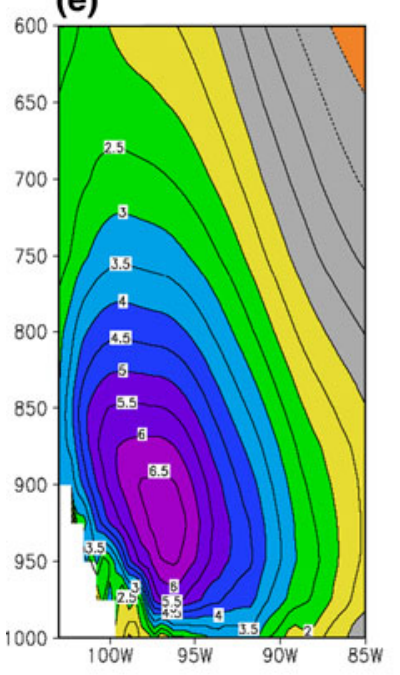

(b)

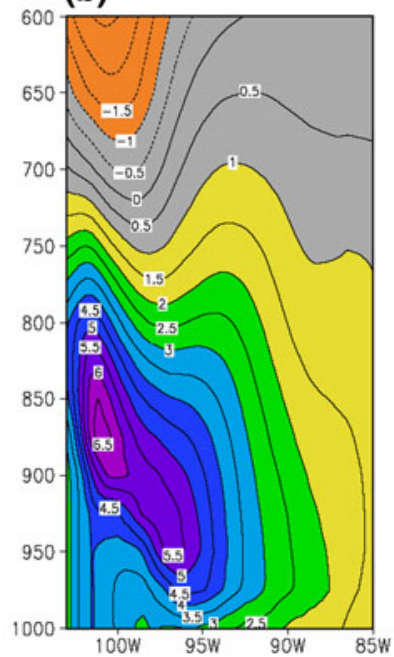

(f)

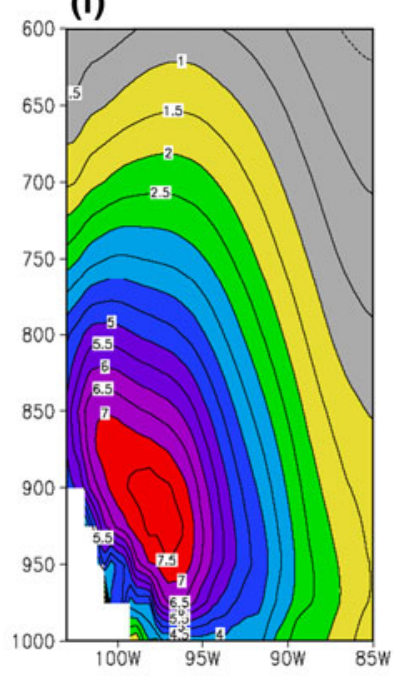

(c)

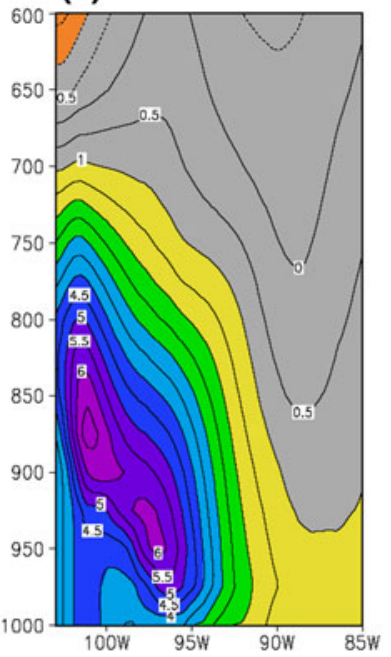

(g)

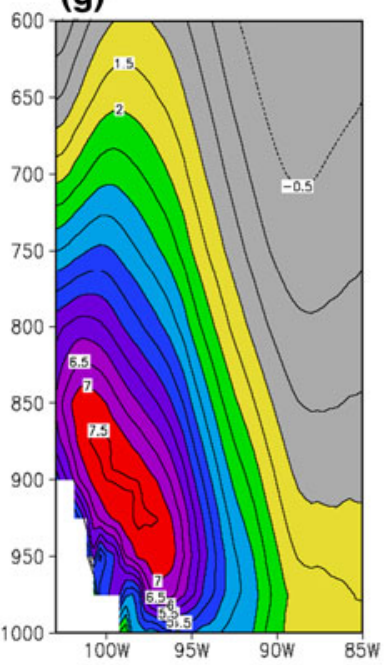

(d)

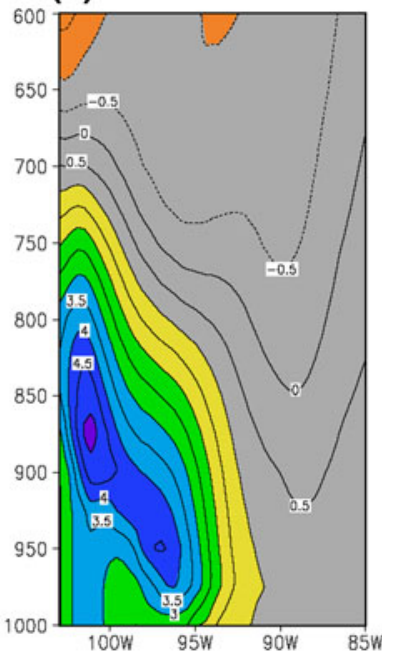

(h)

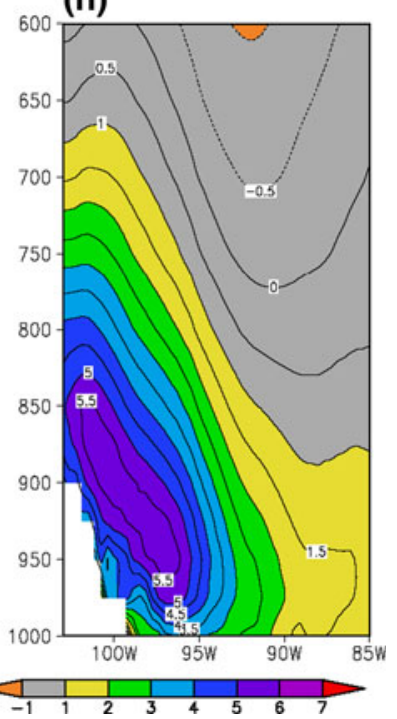

Fig. 1 Vertical cross sections of the climatological meridional velocity $(\mathrm{m} / \mathrm{s})$ averaged from $28^{\circ} \mathrm{N}$ to $34^{\circ} \mathrm{N}$ for a May, b June, c July, and d August from the NARR and for e May, f June, g July,

the diurnal cycle. Figure 2 plots the meridional and horizontal wind at $925 \mathrm{hPa}$ at 3 -h intervals averaged in June from the NARR. The meridional wind is positive throughout the day, but is markedly stronger from 0000 to $0600 \mathrm{LT}$ (Fig. 2c-e). Figure 3 is similar to Fig. 2, but for the L20C simulation. The modeled GPLLJ diurnal cycle is similar to that of the reanalysis. The magnitude of the meridional wind is comparable between L20C and the NARR, with L20C producing a nighttime maximum that is stronger by about $2 \mathrm{~m} / \mathrm{s}$. The RCM also reproduces the location of the core over eastern Texas.

Geopotential heights and winds at $925 \mathrm{hPa}$ are shown in Fig. 4 averaged March/April, May/June, July/August,

h and August from the $30 \mathrm{~km}$ domain of L20C. Contour interval is $0.5 \mathrm{~m} / \mathrm{s}$. Topography is shaded white in the RCM simulation; data is interpolated through the topography in the NARR

and September/October of 1981-2000 from the NCEP-II reanalysis and the $90 \mathrm{~km}$ domain of L20C. The RCM reproduces the strength, position, and seasonal cycle of the NASH, and captures its peak at about $875 \mathrm{gpm}$ in July/August. L20C also simulates the southern extent of the Icelandic Low, with a deeper, more organized center in March/April and September/October than during the summer months. In addition, the simulated features of the NASH and Icelandic Low compare well with the reanalysis during individual years (not shown).

The regional model realistically simulates the GPLLJ and NASH and, as shown in PCI, also produces a reasonable seasonal cycle, diurnal cycle and interannual variability in precipitation over the central US. 
(a) 1800 LT NARR

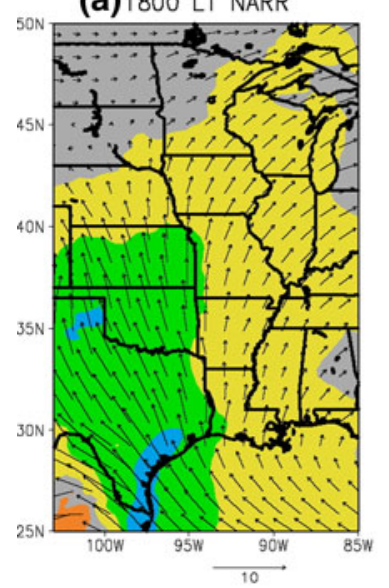

(e) 0600 LT NARR

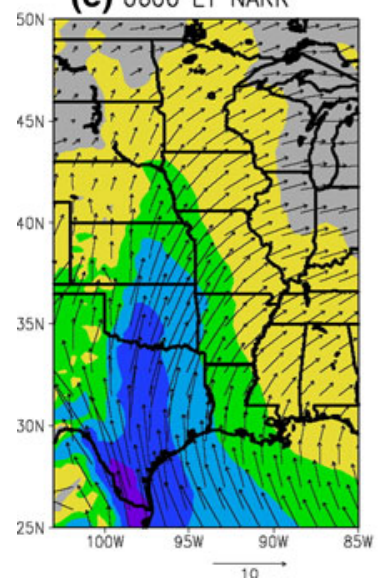

(b) 2100 LT NARR

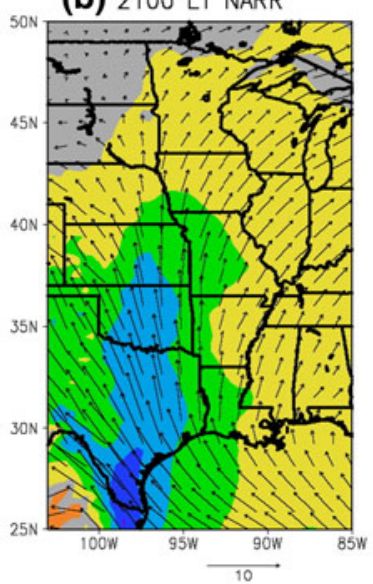

(f) 0900 LT NARR

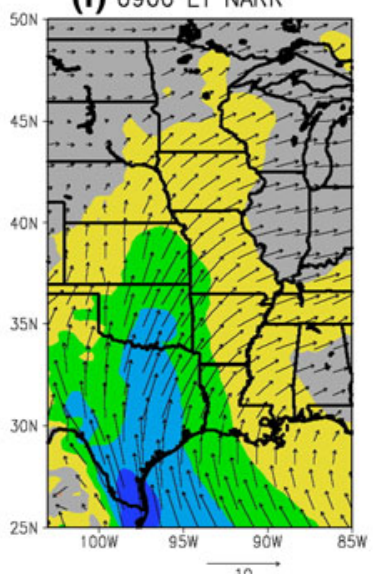

(c) 0000 LT NARR

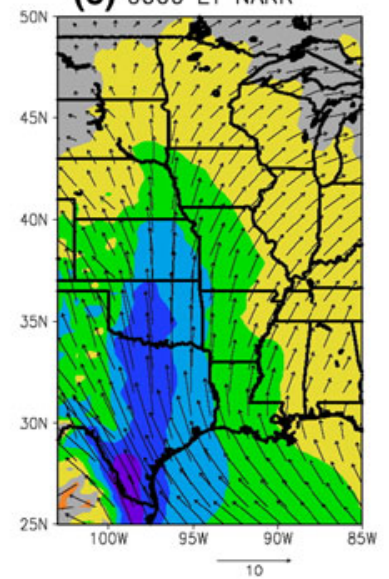

(g) 1200 LT NARR

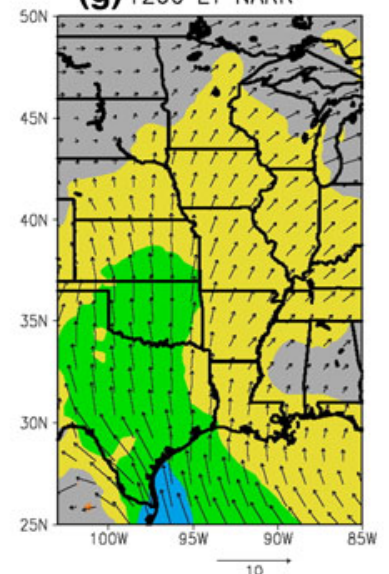

(d) 0300 LT NARR

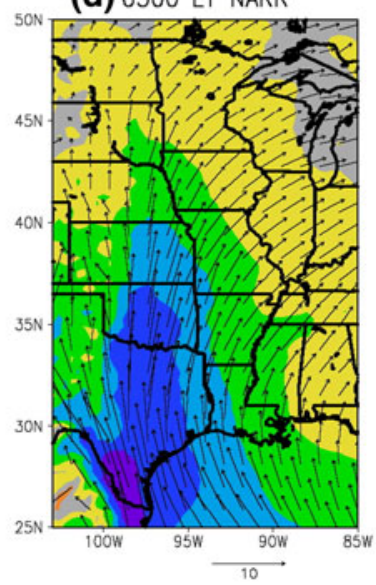

(h) 1500 LT NARR

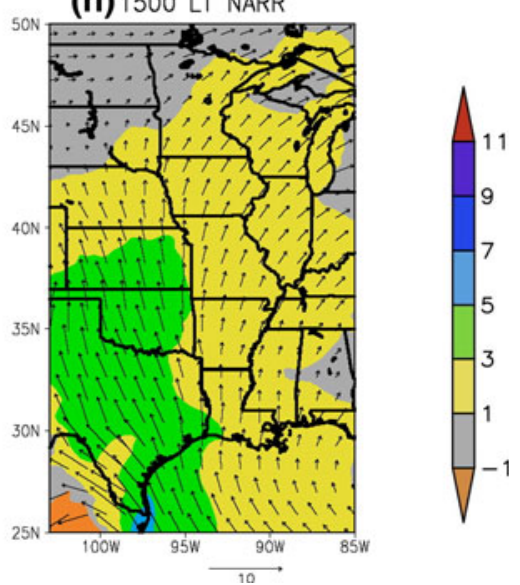

Fig. 2 The June meridional (shaded; m/s) and horizontal (vectors; $\mathrm{m} / \mathrm{s}$ ) wind climatology at $925 \mathrm{hPa}$ at a 1800, b 2100, c 0000, d 0300, e 0600,

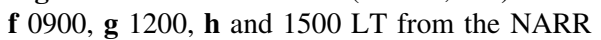

\section{Climate change processes}

A moisture budget analysis, described in Sect. 3, is used to understand the relationships between the regional precipitation projections reported in PCI and large-scale circulation changes. A further understanding of the physical processes responsible for the precipitation changes is gained by considering the diurnal nature of the rainfall projections. This analysis focuses on the northern Great Plains, southern Great Plains, and Midwest regions (defined in PCI, Fig. 4).

Figure 5 shows changes (M21C-L20C) in April precipitation, total (sum of stationary and transient eddy) moisture convergence, stationary moisture convergence, moisture convergence due to transient eddies, evaporation, total moisture advection, stationary moisture advection, and moisture advection due to transient eddy activity, respectively. The residual is not shown since it is relatively small except over the border of Texas and Mexico. As presented in PCI, the future precipitation changes during April (Fig. 5a) are positive over the northern Great Plains centered over Iowa. This is related to positive changes in moisture convergence (Fig. 5b), due primarily to transient eddy activity (Fig. 5d). The precipitation changes occur most strongly at $1800 \mathrm{LT}$ and are near-zero at $0300 \mathrm{LT}$ (not shown), indicating that they are related to enhanced daytime convection, and not to nocturnal low-level jet activity. Since increases in the stationary advection (Fig. $5 \mathrm{~g}$ ) are balanced by decreases in the moisture advection due to transients (Fig. 5h) over much of the central US, the role of changes in total moisture advection (Fig. 5f) is minimal compared to changes moisture convergence. Changes in evaporation (Fig. 5e) also provide a negligible contribution over the central US in April.

Future changes in the moisture budget in May (not shown) are similar to those in April. Wetter conditions over the northern Great Plains are related to changes in stationary and transient moisture convergence, with evaporation playing a minimal role and changes in stationary and transient moisture advection approximately balancing. The positive rainfall changes peak at $2100 \mathrm{LT}$ over the northern Great Plains suggesting, similar to April, a minimal contribution of nocturnal rainfall processes. 

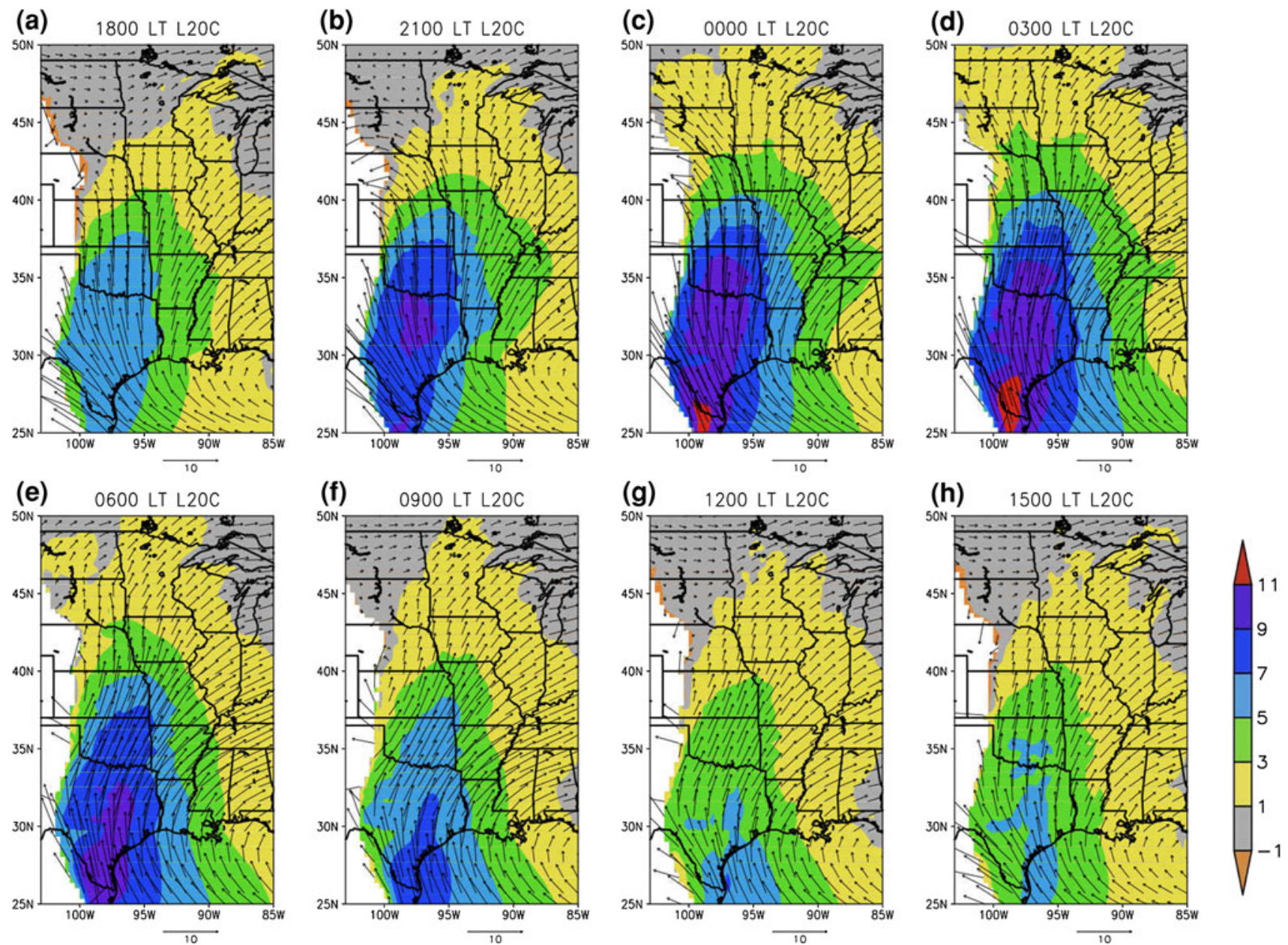

Fig. 3 Similar to Fig. 2, but for the $30 \mathrm{~km}$ domain of L20C. Topography is shaded white

While the climate response is similar in April and May, different physical processes support rainfall changes in June. Figure 6 shows the future changes in the moisture budget in June. As in April and May, changes in evaporation (Fig. 6e) play a negligible role. Over the northern Great Plains, wetter conditions (Fig. 6a) are supported primarily by positive changes in stationary moisture convergence (Fig. 6c). This moisture convergence change is dominated (weakened) by positive meridional (negative zonal) convergence changes (not shown). Total moisture advection changes (Fig. 6f) are weak as the stationary (Fig. 6g) and transient (Fig. 6h) terms again approximately balance.

Over the Midwest, negative precipitation projections are related to negative changes in both the stationary moisture convergence (Fig. 6c), which is dominated by the zonal component and opposed by the meridional component (not shown), as well as the moisture convergence due to transient eddies (Fig. 6d). Total moisture advection changes (Fig. 6f) are also important, as positive moisture advection changes due to transient eddy activity (Fig. 6h) oppose the negative moisture convergence changes.
Analyzing changes in the diurnal cycle enables a more complete understanding of the connection between the precipitation and circulation changes. The 3-hourly precipitation changes in June over the northern Great Plains and the Midwest are shown in Fig. 7. Changes in the diurnal cycle are strong over the northern Great Plains, with maximum precipitation increases of $0.3 \mathrm{~mm} /$ day occurring from 0000 to $0600 \mathrm{LT}$ and a minimum of no change at $1200 \mathrm{LT}$, suggesting that changes in the nocturnal GPLLJ are supporting the future rainfall changes. Over the Midwest, drying peaks at over $-0.5 \mathrm{~mm} /$ day at $0000 \mathrm{LT}$ and 1500 LT, suggesting both a connection with the GPLLJ as well as a contribution from suppressed daytime convection.

By investigating the connection between the changes in moisture convergence and low-level wind convergence, the role of the GPLLJ in supporting the future rainfall in June becomes clearer. The pattern of vertically-integrated lowlevel (surface-775 hPa) atmospheric convergence changes in June (not shown) resembles that of the changes in vertically-integrated stationary moisture convergence (Fig. 6c), indicating that the spatial pattern of the moisture 
Fig. 4 Climatological geopotential heights (gpm) and wind vectors $(\mathrm{m} / \mathrm{s})$ at $925 \mathrm{hPa}$ averaged a March-April, b May-June, c July-August, and $\mathbf{d}$ September-October from the NCEP II reanalysis and e March-April, f May-June, g July-August, and

h September-October from the $90 \mathrm{~km}$ domain of L20C.

Topography is shaded white in the RCM simulation; data is interpolated through the topography in the reanalysis (a) NCEPII Mar-Apr

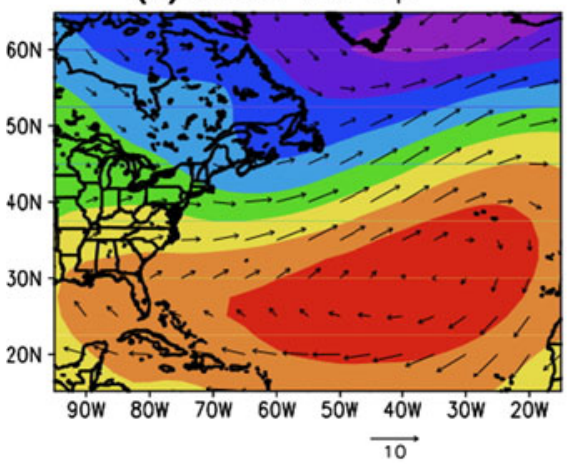

(b) NCEPII May-Jun

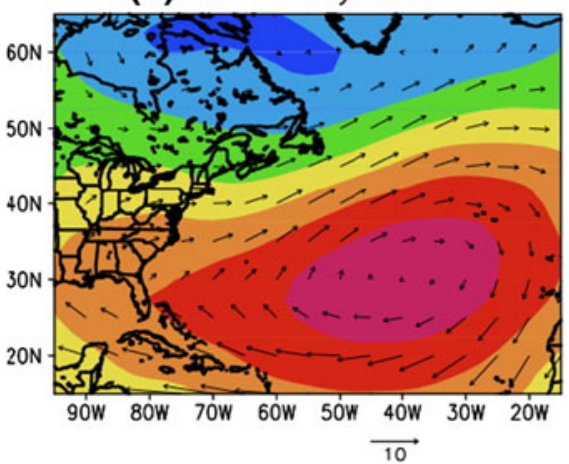

(c) NCEPII Jul-Aug

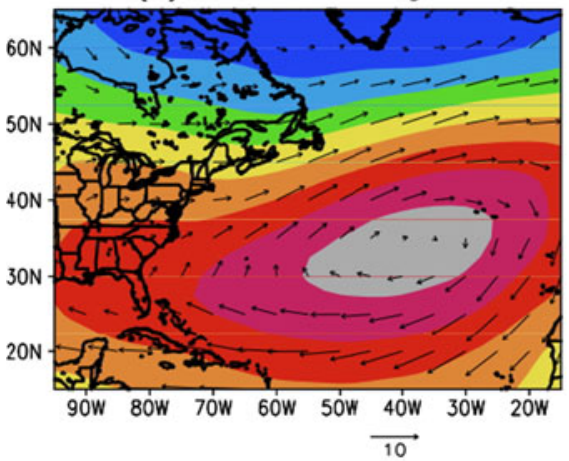

(d) NCEP\| Sep-Oct

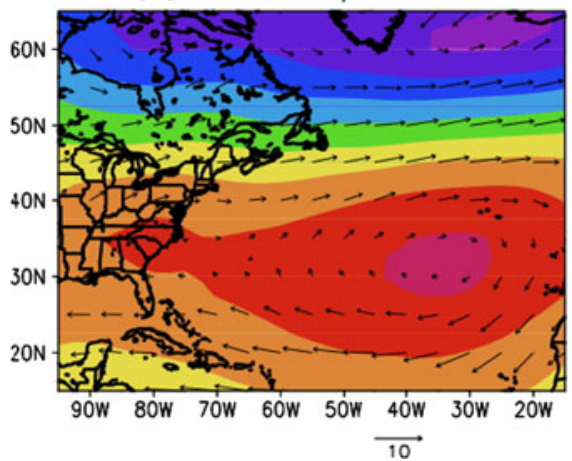

(e) L20C Mar-Apr

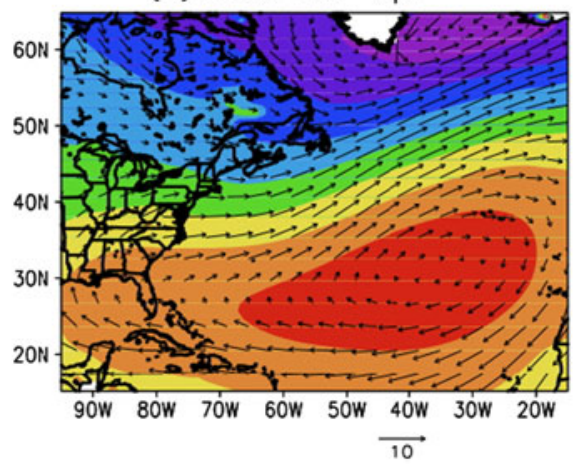

(f) L20C May-Jun

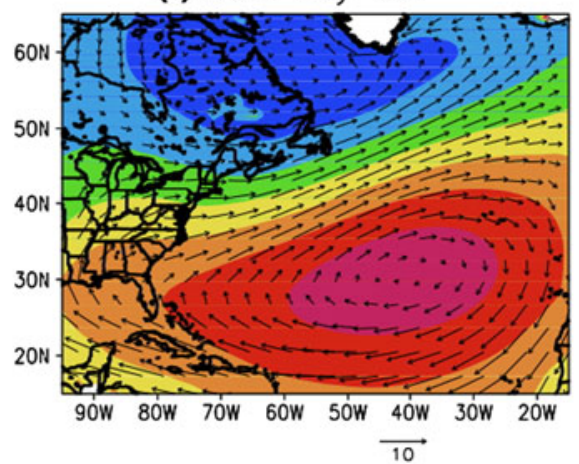

(g) L20C Jul-Aug

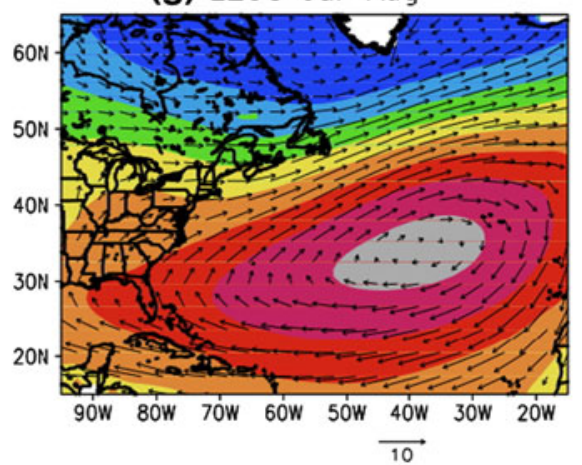

(h) L20C Sep-0ct

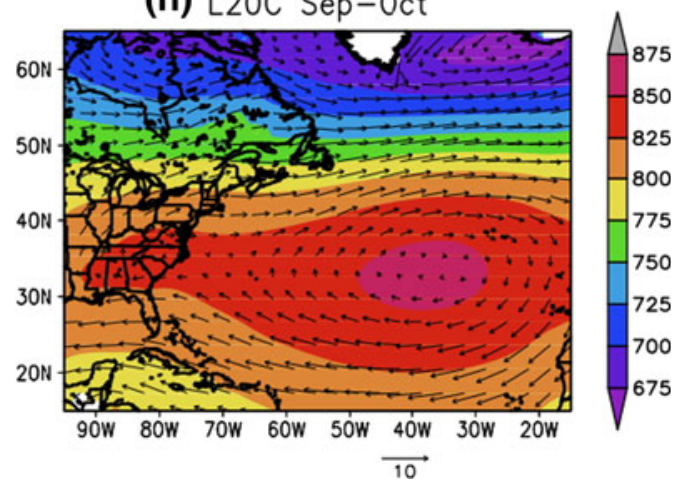

convergence change is dominated by changes in the wind field, not by changes in atmospheric moisture. In addition, the changes in 3-hourly low-level atmospheric convergence have a diurnal cycle that matches the changes in the diurnal precipitation, with the strongest convergence occurring between 0000 and 0600 LT over the northern Great Plains, further supporting a connection between the rainfall changes and the GPLLJ. 

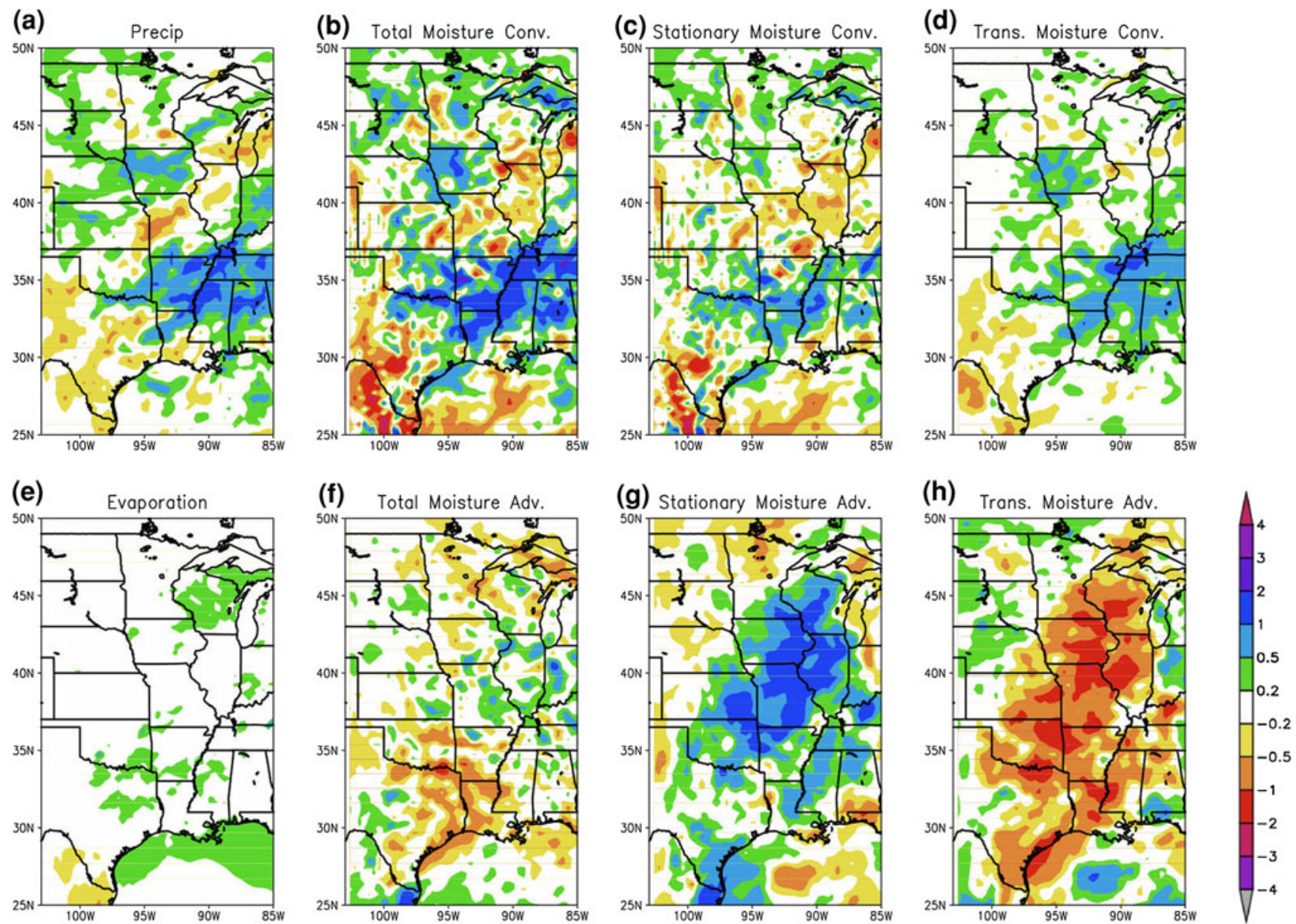

Fig. 5 Future changes from M21C-L20C in a precipitation, b total vertically-integrated moisture convergence, $\mathbf{c}$ vertically-integrated stationary moisture convergence, $\mathbf{d}$ vertically-integrated moisture convergence due to transient eddies, $\mathbf{e}$ evaporation, $\mathbf{f}$ total vertically-

Figure 8a displays future changes (M21C-L20C) in meridional and horizontal wind at $925 \mathrm{hPa}$ in June averaged 0000-0600 LT. In the mid-twenty-first century the nocturnal GPLLJ is strengthened, especially north of the core in the jet exit region. Since the geostrophic wind is nondivergent, we remove the geostrophic component to identify the changes in the full wind field that contribute to the convergence. Figure 8b, c show the ageostrophic meridional and horizontal wind at $925 \mathrm{hPa}$ in June averaged 0000-0600 LT from L20C and the future changes (M21C-L20C), respectively. Like the full wind (Figs. 2, 3 ), the ageostrophic wind demonstrates a significant diurnal cycle. In June of L20C the ageostrophic component of the GPLLJ peaks between 0000 and 0600 LT (Fig. 8b). In the hours before and after the peak of the GPLLJ, the meridional ageostrophic wind is still southerly, but weaker, and at $1200-1500$ LT is northerly (not shown) in L20C.

Compared with the full wind changes (Fig. 8a), the ageostrophic wind changes at 0000-0600 LT in June (Fig. 9c) are similar in pattern but weaker in magnitude,

integrated moisture advection, $\mathbf{g}$ vertically-integrated stationary moisture advection, and $\mathbf{h}$ vertically-integrated moisture advection due to transient eddies for April from the $30 \mathrm{~km}$ domain. Units are $\mathrm{mm} /$ day

with a stronger southerly ageostrophic wind reaching as far north as Iowa. These changes in the meridional ageostrophic wind at 0000-0600 LT contribute significantly to the increased stationary moisture convergence (Fig. 6c) that is associated with enhanced precipitation in the northern Great Plains in the future (Fig. 6a). The full and ageostrophic wind changes at 0000-0600 LT in June are more zonally oriented over the Midwest (Fig. 8a, c) and contribute to the negative stationary moisture convergence changes (Fig. 8c) that support future precipitation decreases there.

The strengthening of the GPLLJ in June is concurrent with a strengthening and westward extension of the NASH over the eastern US (Fig. 9a) that is remarkably similar to AOGCM projections (Cook et al. 2008b, Fig. 6) and has been observed on decadal time scales in the summer, presumably in association with global warming ( $\mathrm{Li}$ et al. 2011). Also as in the AOGCM projections (Cook et al. 2008b, Fig. 8), the future land-surface temperature over the continental US warms more than the SST in the North 
(a)

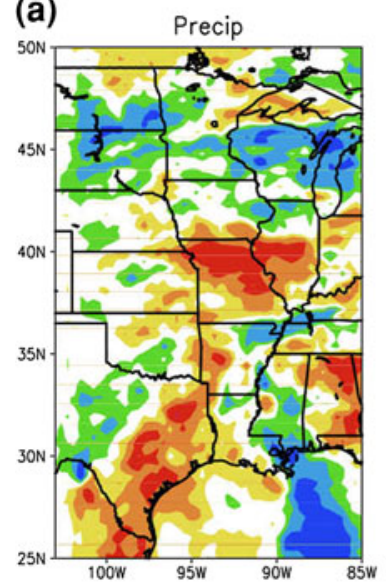

(e)

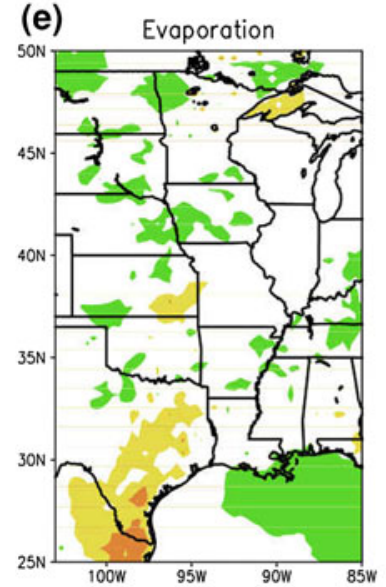

(b) Total Moisture Conv.

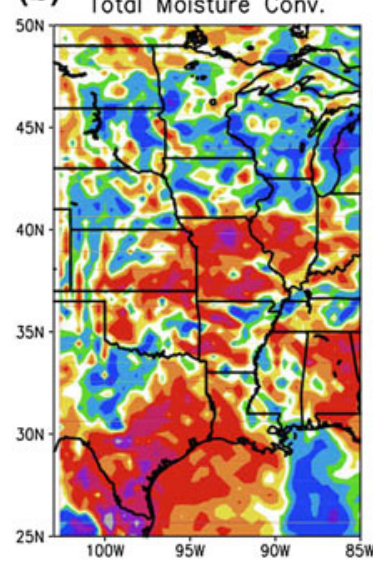

(f) Total Moisture Adv.

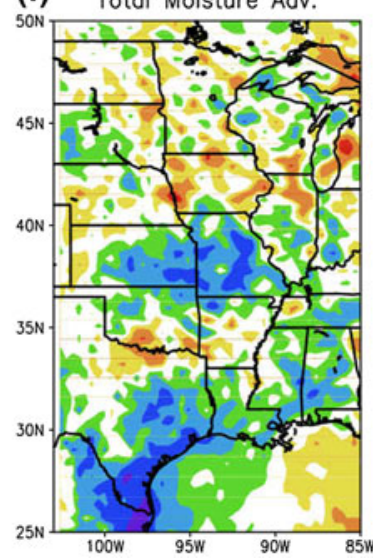

(c)

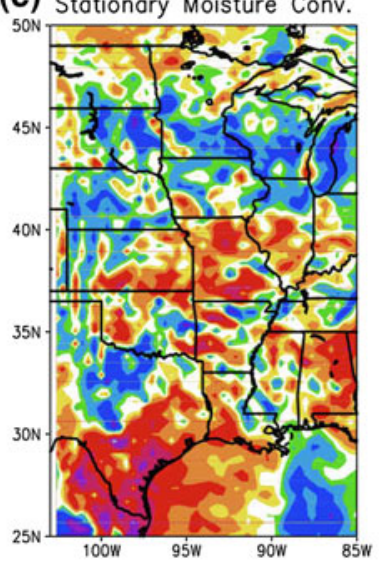

(g)

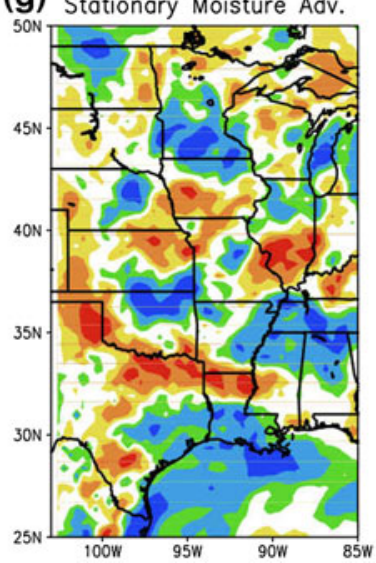

(d)

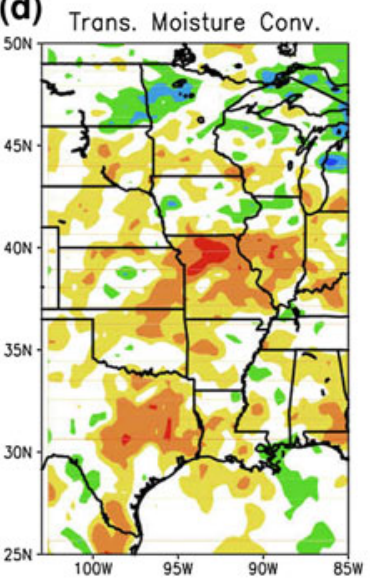

(h) Trans. Moisture Adv.

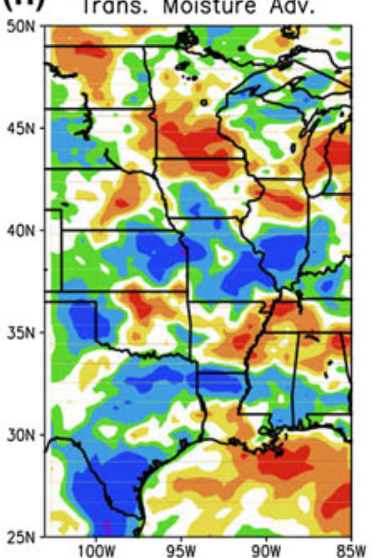

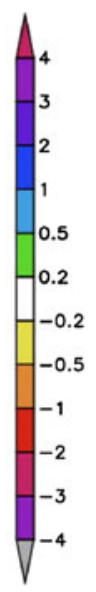

Fig. 6 Similar to Fig. 5, but for June

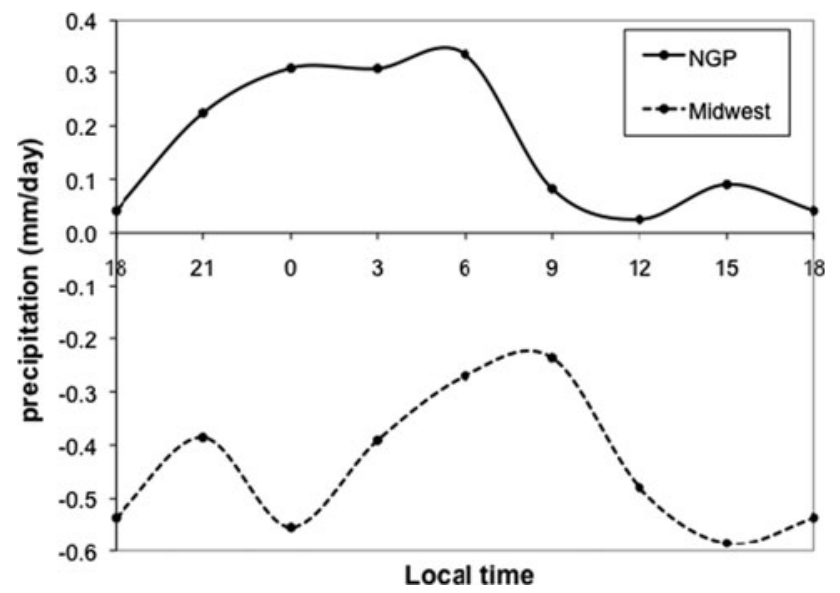

Fig. 7 Future changes (M21C-L20C) in precipitation (mm/day) averaged during June on the 3-hourly timescale over the northern Great Plains (solid) and Midwest (dashed)

Atlantic (Fig. 9b). These projected changes in the GPLLJ, $\mathrm{NASH}$, and land/sea temperature gradient in June are consistent with the relationships simulated in the idealized GCM experiments of Weaver et al. (2009b).
The enhanced anticyclonic circulation from the westward expansion of the NASH places stronger southerly low-level wind over the central US, which enhances moisture transport to the Great Plains and Midwest from the Gulf of Mexico. Positive changes in the total future low-level (surface to $750 \mathrm{hPa}$ ) moisture transport (Fig. 9c) are due primarily to meridional transport increases (Fig. 9d) over the southern Great Plains, which are supported by both increases in low-level water vapor (Fig. 9f) and stronger meridional wind at $925 \mathrm{hPa}$ (Fig. 9g). Over the Midwest, the total moisture transport is dominated by the zonal component (Fig. 9e) and is supported largely by the strengthened zonal flow (Fig. 9h) as the enhanced GPLLJ curves to the east, as well as by water vapor increases. By identifying the connection of changes in the moisture transport to the GPLLJ, which is related to the $\mathrm{NASH}$, which is modulated by land/sea contrast, we are able to link regional-scale projections to large-scale changes that are related to greenhouse gas induced warming. It is encouraging that the simulated precipitation changes, which are based on parameterizations rather than physical equations, are consistent with the circulation changes. This, 
(a) M21C-L20C V

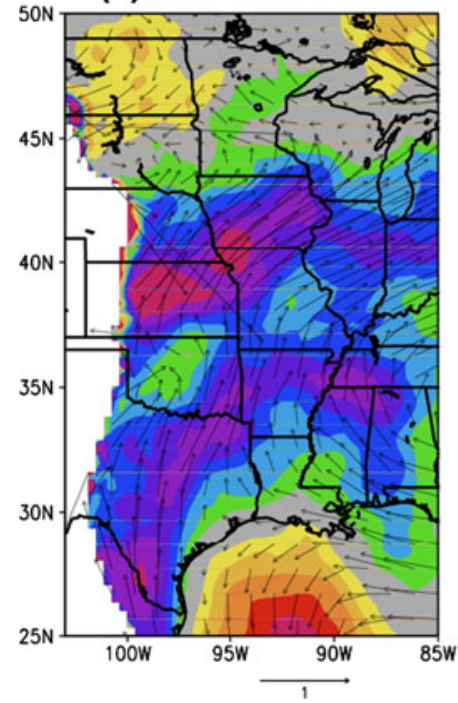

(b) L20C Vag

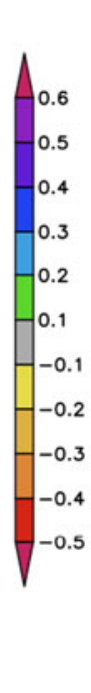

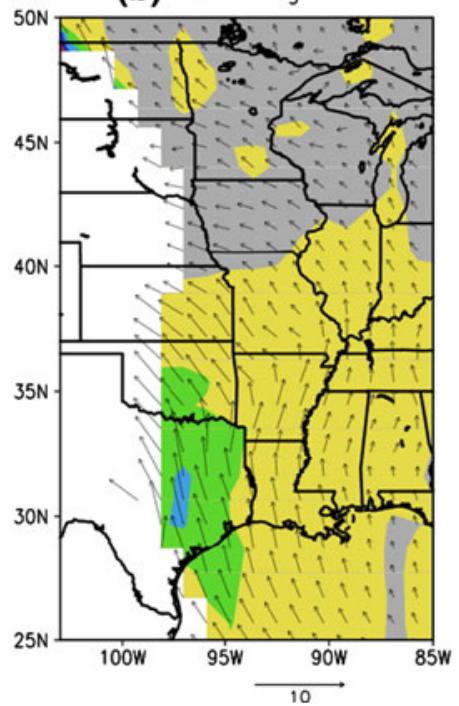

(c) $\mathrm{M} 21 \mathrm{C}-\mathrm{L} 20 \mathrm{C} \mathrm{Vag}$

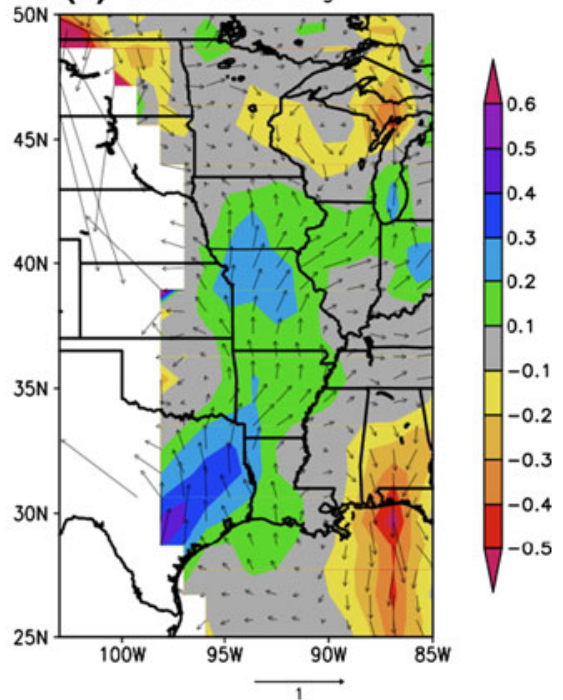

Fig. 8 The a future changes (M21C-L20C) in the meridional wind (shaded) and horizontal wind (vector), $\mathbf{b}$ meridional ageostrophic wind (shaded) and horizontal ageostrophic wind (vector) from L20C, and

(shaded) and horizontal ageostrophic wind (vector) at $925 \mathrm{hPa}$ averaged 0000-0600 LT during June. Units are $\mathrm{m} / \mathrm{s}$ and topography is shaded white. The scales are the same for (b) and Fig. 3 and for (a) and (c)

(a)

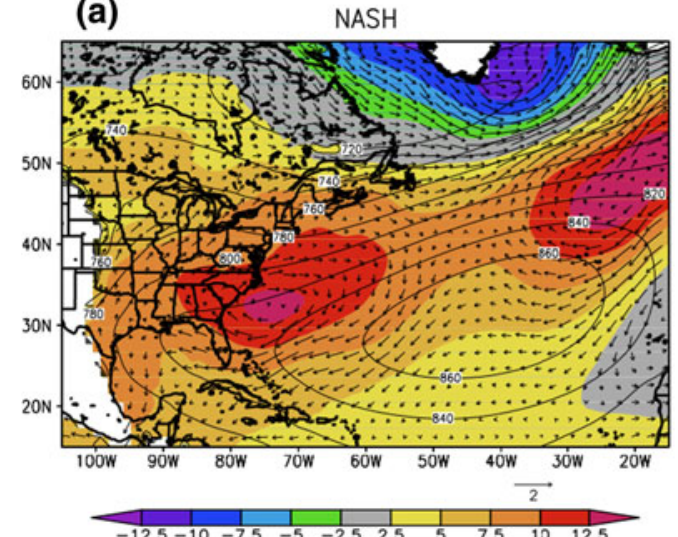

(b)

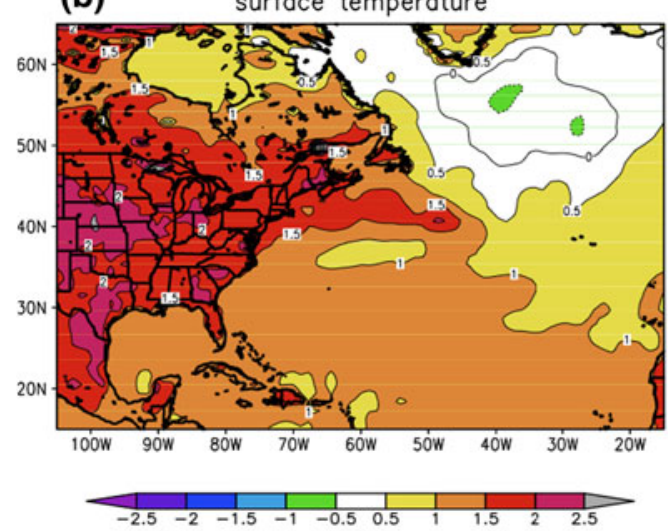

(c) moisture transp.

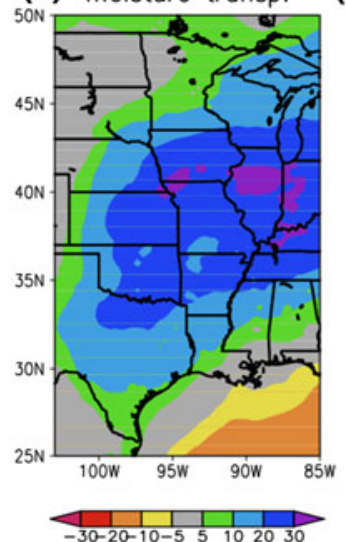

(f) V.I. water vapor

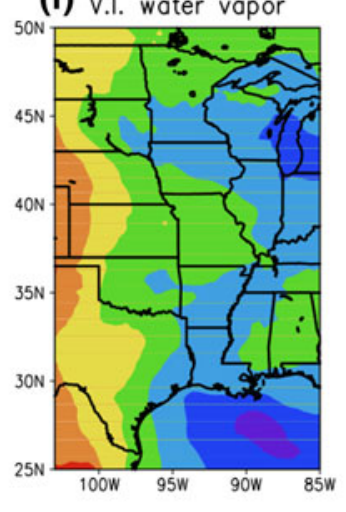

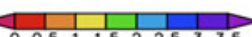

(d) merid. moisture transp.

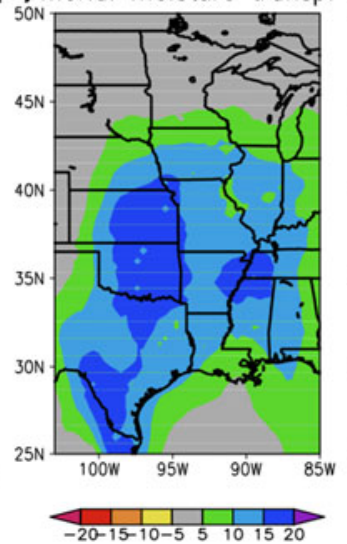

(e) zonal moisture transp.

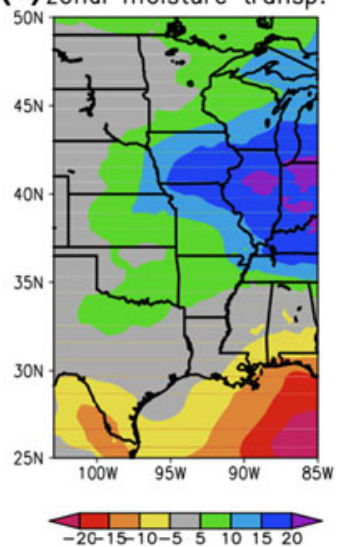

(g) $\quad \vee 925 \mathrm{hPa}$

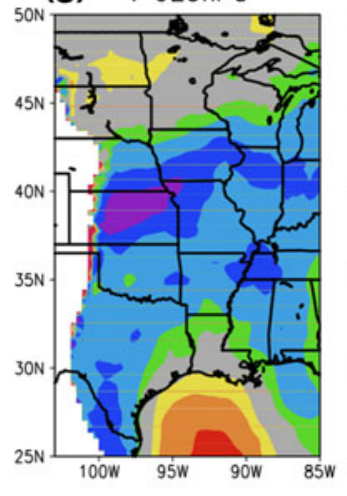

(h) u $925 \mathrm{hPa}$

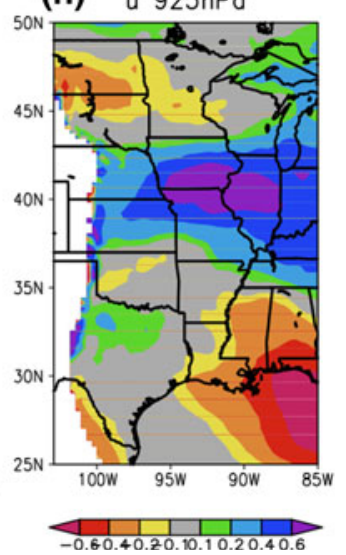

Fig. 9 Future changes (M21C-L20C) in a geopotential heights (shaded; gpm) and horizontal wind (vector; $\mathrm{m} / \mathrm{s}$ ) with geopotential heights from L20C (contour; gpm) at $925 \mathrm{hPa}$ and b surface temperature $(\mathrm{K})$ from the $90 \mathrm{~km}$ domain and $\mathbf{c}$ total, d meridional, and e zonal low-level (surface to $750 \mathrm{hPa}$ ) moisture transport $\left(\mathrm{kg} \mathrm{m}^{-1} \mathrm{~s}^{-1}\right.$ ), f vertically integrated low-level (surface to $750 \mathrm{hPa}$ ) water vapor mixing ratio $\left(\mathrm{kg} \mathrm{m}^{-2}\right)$, and $\mathbf{g}$ meridional and $\mathbf{h}$ zonal wind at $925 \mathrm{hPa}(\mathrm{m} / \mathrm{s})$ from the $30 \mathrm{~km}$ domain during June 

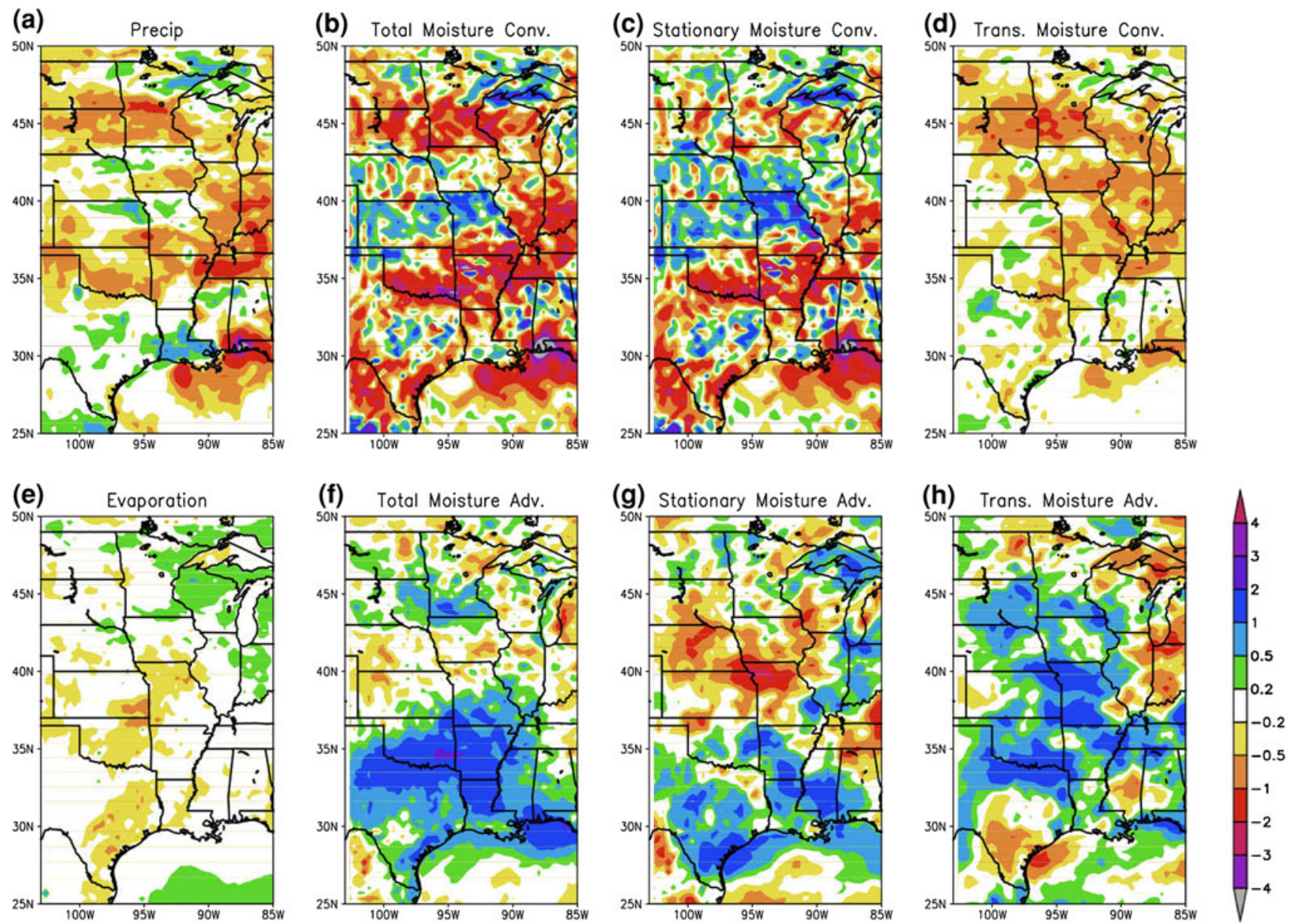

Fig. 10 Similar to Fig. 5, but for July

along with the agreement among the RCM and AOGCM rainfall and circulation projections, adds to the confidence in the predictions.

While the precipitation projections in June are primarily associated with moisture convergence changes, advection changes are increasingly important in July. Future changes in the moisture budget in July are shown in Fig. 10. Precipitation projections are negative over the northern and southern Great Plains and Midwest (Fig. 10a). Over the southern Great Plains the negative precipitation response is dominated by negative stationary moisture convergence changes (Fig. 10c) and is weakened by positive stationary (Fig. $10 \mathrm{~g}$ ) and transient (Fig. 10h) moisture advection changes, while negative changes in moisture convergence due to transient eddies (Fig. 10d) are most important over the northern Great Plains. The rainfall deficit is strongest at $1800 \mathrm{LT}$ (1500 LT) over the southern (northern) Great Plains, suggesting the importance of reduced daytime convection, with a secondary minimum at 0900 LT (0300-0600 LT). Over the Midwest future drying is mainly related to negative moisture convergence changes, with little contribution from changes in advection, and occur most strongly at $0000 \mathrm{LT}$.
Figure 11 shows the future change in precipitation, evaporation, moisture convergence due to transient eddies, and the sum of the stationary and transient moisture convergence and advection and the residual, in August. As in July, the future drying over the northern Great Plains is supported by negative changes in moisture convergence due to transients (Fig. 11c), but unlike the previous months, decreased evaporation (Fig. 11b) also largely supports the drying. When considering all moisture budget terms combined except for evaporation (Fig. 11d), the change over the northern Great Plains is weakly positive, indicating that the drying contribution due to the negative changes in transient moisture convergence is compensated by the other dynamical terms. The importance of changes in evaporation in the late summer suggests that, similar to the present day mechanism for prolonging and intensifying droughts (e.g., Hong and Kalnay 2000; Schubert et al. 2004; Wu and Kinter 2009), the soil moisture has provided a memory of the drying from the previous month, which was initiated by negative changes in moisture convergence due to transients. Since precipitation minus evaporation is negative in July and August in L20C (and in present day 
Fig. 11 Future changes

(M21C-L20C) in

a precipitation, b evaporation,

c vertically-integrated moisture convergence due to transient eddies, and $\mathbf{d}$ the sum of vertically-integrated stationary and transient moisture convergence and advection and residual for August from the $30 \mathrm{~km}$ domain. Units are $\mathrm{mm} /$ day
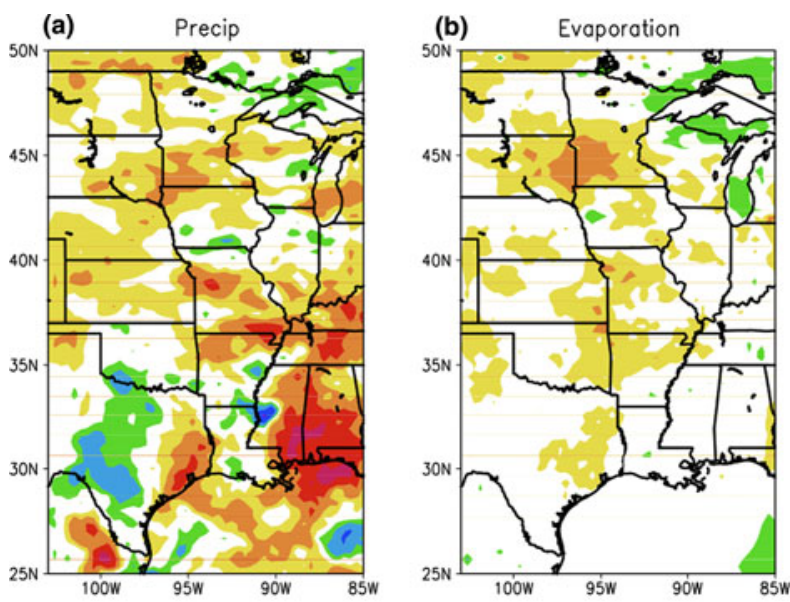

(c) Trans. Moisture Conv.

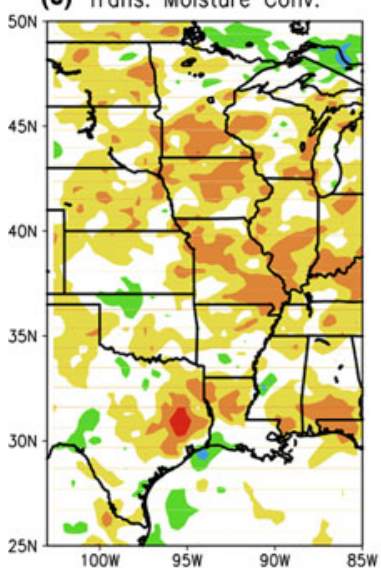

observations), the projected rainfall deficit in July desiccates the ground and results in a further decreased soil moisture supply in August. A similar breakdown of the moisture budget in the following month suggests that this mechanism prolongs the drying through September.

\section{Conclusions}

A regional model with $30-\mathrm{km}$ resolution over the central US is validated and used to project changes in US precipitation for the mid-twenty-first century in Patricola and Cook (2012; PCI). Here, the 20-year ensemble simulations representing the late twentieth century and mid-twenty-first century are further analyzed to reveal the physical processes of those projections to add to the evaluation of confidence in the projections.

An atmospheric moisture budget analysis is used to relate future changes in precipitation to changes in evaporation, atmospheric water vapor, and circulation fields to connect the regional-scale precipitation changes to the global greenhouse-forcing. Since central US precipitation has maxima related to afternoon convection and nocturnal low-level jet events, an examination of the diurnal rainfall cycle provides additional information about the physical processes of the simulated regional precipitation projections.

The projected central US precipitation changes are related to different physical processes during the spring and summer. In April and May, positive rainfall projections occur most strongly in the afternoon and evening hours and are supported largely by positive changes in moisture convergence due to transient eddies, indicating enhanced daytime convection. Such enhanced convection could be the result of warming of the surface air, associated directly or indirectly with local greenhouse gas forcing.

During June, increased rainfall over the northern Great Plains is strongest from 0000 to $0600 \mathrm{LT}$ and is supported by positive changes in stationary meridional moisture convergence related to a strengthening of the GPLLJ, especially in the jet exit region. This response is accompanied by an intensification of the western portion of the $\mathrm{NASH}$, related to the greenhouse gas forcing through Atlantic SSTAs and, in particular, the differential low-level warming over continental and ocean surfaces. By linking the regional-scale changes in precipitation and the GPLLJ 
to large-scale changes in the NASH and surface temperature induced by greenhouse gas warming, we identify precipitation and circulation changes consistent with our understanding of present-day climate variability. This, and the agreement in rainfall and circulation projections between the RCM and AOGCMs (Cook et al. 2008b), adds confidence to the predictions.

Over the Midwest, decreased rainfall in June is strongest at $1500 \mathrm{LT}$ and $0000 \mathrm{LT}$ and is supported by negative changes in both moisture convergence due to transient eddies and zonal stationary convergence, indicating the importance of both suppressed daytime convection as well as changes in the zonal flow in the GPLLJ exit region.

Future drying over the northern Great Plains is initiated in July by weakened daytime convection, as suggested by the significant contribution from negative changes in moisture convergence due to transient eddies and the occurrence of the maximum anomaly in the afternoon. Drying over the northern Great Plains persists throughout August and September when the deficit in soil moisture and strong land-atmosphere feedbacks become important.

Acknowledgments Support for this work from the Department of Energy BER Program (Award DE-SC0005223) is gratefully acknowledged. We also thank the Texas Advanced Computing Center (TACC), where the simulations were run. The authors thank S. Nigam, one anonymous reviewer, E. K. Vizy, P. Hess, and S. Colucci for their comments.

Open Access This article is distributed under the terms of the Creative Commons Attribution License which permits any use, distribution, and reproduction in any medium, provided the original author(s) and the source are credited.

\section{References}

Blackadar AK (1957) Boundary layer wind maxima and their significance for the growth of nocturnal inversions. Bull Am Meteorol Soc 38:282-290

Bonner WD (1968) Climatology of the low level jet. Mon Weather Rev 96:833-850

Cook BI, Miller RL, Seager R (2008a) Dust and sea surface temperature forcing of the $1930 \mathrm{~s}$ "Dust Bowl" drought. Geophys Res Lett 35:L08710. doi:10.1029/2008GL033486

Cook KH, Vizy EK, Launer ZS, Patricola CM (2008b) Springtime intensification of the Great Plains low-level jet and Midwest precipitation in GCM simulations of the twenty-first century. J Clim 21:6321-6340

Dirmeyer PA, Brubaker KL (1999) Contrasting evaporative moisture sources during the drought of 1988 and the flood of 1993. J Geophys Res 104:19383-19397

Dirmeyer PA, Koster RD, Guo ZC (2006) Do global models properly represent the feedback between land and atmosphere? J Hydrometeorol 7:1177-1198. doi:10.1175/JHM532.1

Egan T (2006) The worst hard time: the untold story of those who survived the Great American Dust Bowl. Houghton Mifflin Company, Boston
Hoerling M, Quan X-W, Eischeid J (2009) Distinct causes for two principal US droughts of the 20th century. Geophys Res Lett 36:L19708. doi:10.1029/2009GL039860

Holton JR (1967) The diurnal boundary layer wind oscillation above sloping terrain. Tellus 19:199-205

Hong S-Y, Kalnay E (2000) Role of sea surface temperature and soilmoisture feedback in the 1998 Oklahoma-Texas drought. Nature 408:842-844

IPCC (2000) Emissions scenarios. In: Nakicenovic N, Swart R (eds) Cambridge University Press, Cambridge, $570 \mathrm{pp}$

Jiang X, Lau N-C, Held IM, Ploshay JJ (2007) Mechanisms of the Great Plains low-level jet as simulated in an AGCM. J Atmos Sci 64:532-547

Kanamitsu M, Ebisuzaki W, Woollen J, Yang S-K, Hnilo JJ, Fiorino M, Potter GL (2002) NCEP-DOE AMIP-II Reanalysis (R-2). Bull Am Meteorol Soc 83:1631-1643

Koster RD et al (2004) Regions of strong coupling between soil moisture and precipitation. Science 305(5687):1138-1140

Lenters JD, Cook KH (1995) Simulation and diagnosis of the regional summertime precipitation climatology in South America. J Clim 8:2988-3005

Li W, Laifang L, Fu R, Deng Y, Wang H (2011) Changes to the North Atlantic subtropical high and its role in the intensification of summer rainfall variability in the southeastern United States. J Clim 24:1499-1506

Mesinger F et al (2006) North American regional reanalysis. Bull Am Meteorol Soc 87:343-360

Mo KC, Paegle JN, Higgins RW (1997) Atmospheric processes associated with summer floods and droughts in the Central United States. J Clim 10:3028-3046

Nigam S, Ruiz-Barradas A (2006) Seasonal hydroclimate variability over North America in global and regional reanalyses and AMIP simulations: varied representation. J Clim 19:815-837. doi: 10.1175/JCLI3635.1

Nigam S, Guan B, Ruiz-Barradas A (2011) Key role of the Atlantic Multidecadal Oscillation in 20th century drought and wet periods over the Great Plains. Geophys Res Lett 38:L16713. doi: 10.1029/2011GL048650

Paeth H, Latif M, Hense A (2003) Global SST influence on twentieth century NAO variability. Clim Dyn 21:63-75

Patricola CM, Cook KH (2012) Mid-twenty-first century climate change in the Central United States. Part I: regional and global model predictions. Clim Dyn (in review)

Roads JO, Chen S-C, Guetter AK, Georgakakos KP (1994) Largescale aspects of the United States hydrologic cycle. Bull Am Meteorol Soc 75:1589-1610

Ruiz-Barradas A, Nigam S (2005) Warm season rainfall variability over the US Great Plains in observations, NCEP and ERA-40 reanalyses, and NCAR and NASA atmospheric model simulations. J Clim 18:1808-1830

Schubert SD, Suarez MJ, Pegion PJ, Koster RD, Bacmeister JT (2004) On the cause of the 1930s Dust Bowl. Science 303:1855-1859

Schubert SD, Suarex MJ, Pegion PJ, Koster RD, Bacmeister JT (2007) Predictability of long-term drought and pluvial conditions in the US Great Plains. J Clim 21:802-816

Seager R, Kushnir Y, Ting M, Cane M, Naik N, Miller J (2008) Would advance knowledge of the 1930s SSTs have allowed prediction of the dust bowl drought? J Clim 21:3261-3280

Skamarock WC, Klemp JB, Dudhia J, Gill DO, Barker DM, Wang W, Powers JG (2008) A description of the advanced research WRF version 2. NCAR/TN-408 + STR, $88 \mathrm{pp}$

Ting M, Wang H (2006) The role of the North American topography on the maintenance of the Great Plains summer low-level jet. J Atmos Sci 63:1056-1068 
Tollerud EI, Caracena F, Koch SE, Jamison BD, Hardesty RM, McCarty BJ, Kiemle C, Collander RS, Bartels DL, Albers S, Shaw B, Birkheuer DL, Brewer WA (2008) Mesoscale moisture transport by the low-level jet during the IHOP field experiment. Mon Weather Rev 136:3781-3795

Trenberth KE, Branstator GW (1992) Issues in establishing causes of the 1988 drought over North America. J Clim 5:159-172

Trenberth KE, Branstator GW, Arkin PA (1988) Origins of the 1988 North American drought. Science 242:1640-1645

Weaver SJ, Nigam S (2008) Variability of the Great Plains low-level jet: large-scale circulation context and hydroclimate impacts. J Clim 21:1532-1551

Weaver SJ, Ruiz-Barradas A, Nigam S (2009a) Pentad evolution of the 1988 drought and 1993 flood over the Great Plains: an NARR perspective on the atmospheric and terrestrial water balance. J Clim 22:5366-5384
Weaver SJ, Schubert S, Wang H (2009b) Warm season variations in the low-level circulation and precipitation over the central United States in observations, AMIP simulations, and idealized SST experiments. J Clim 22(5401):5420

Wu R, Kinter JL (2009) Analysis of the relationship of US droughts with SST and soil moisture: distinguishing the time scale of droughts. J Clim 22:4520-4538

Wu Y, Raman S (1998) The Summertime Great Plains Low Level Jet And The Effect of Its Origin On Moisture Transport. Boundary Layer Met 88:445-466

Zhang J, Wang W-C, Leung LR (2008) Contribution of landatmosphere coupling to summer climate variability over the contiguous United States. J Geophys Res 113:D22109. doi: 10.1029/2008JD010136 